\title{
1 A universal model for carbon dioxide uptake by plants
}

3 Han Wang ${ }^{1,2^{*}}$, I. Colin Prentice ${ }^{1,2,3}$, William K. Cornwell ${ }^{4}$, Trevor F. Keenan ${ }^{2}$, Tyler W. Davis ${ }^{3,5}$, Ian J.

4 Wright $^{2}$, Bradley J. Evans ${ }^{2,6}$ and Changhui Peng ${ }^{1,7^{*}}$

$6{ }^{1}$ State Key Laboratory of Soil Erosion and Dryland Farming on the Loess Plateau, College of Forestry, 7 Northwest A \& F University, Yangling 712100, China

$8 \quad{ }^{2}$ Department of Biological Sciences, Macquarie University, North Ryde, NSW 2109, Australia

$9{ }^{3}$ AXA Chair of Biosphere and Climate Impacts, Grand Challenges in Ecosystems and the Environment 10 and Grantham Institute - Climate Change and the Environment, Department of Life Sciences, Imperial

11 College London, Silwood Park Campus, Buckhurst Road, Ascot SL5 7PY, UK

$12{ }^{4}$ Ecology and Evolution Research Centre, School of Biological, Earth and Environmental Sciences, 13 The University of New South Wales, Randwick, NSW 2052, Australia

$14{ }^{5}$ Robert W. Holley Center for Agriculture and Health, United States Department of Agriculture15 Agricultural Research Service, Ithaca, NY 14853, United States

$16{ }^{6}$ Faculty of Agriculture and Environment, Department of Environmental Sciences, The University of 17 Sydney, NSW 2006, Australia

$18{ }^{7}$ Department of Biological Sciences, Institute of Environmental Sciences, University of Quebec at 19 Montreal, C.P. 8888, Succ. Centre-Ville, Montréal H3C 3P8, Québec, Canada

$21{ }^{*}$ Correspondence to:

22 H Wang: wanghan_sci@yahoo.com, C Peng: peng.changhui@uqam.ca 


\section{Abstract}

The rate of carbon uptake by land plants depends on the ratio of leaf-internal to ambient carbon dioxide partial pressures ${ }^{1}$, here termed $\chi$. This quantity is a key determinant of both primary production and transpiration and the relationship between them. But current models for $\chi$ are empirical and incomplete, contributing to the many uncertainties afflicting model estimates and future projections of terrestrial carbon uptake ${ }^{2,3}$. Here we show that a simple evolutionary optimality hypothesis ${ }^{4,5}$ generates functional relationships between $\chi$ and growth temperature, vapour pressure deficit and elevation that are precisely and quantitatively consistent with empirical $\chi$ values from a worldwide data set containing $>3500$ stable carbon isotope measurements. A single global equation embodying these relationships then unifies the empirical light use efficiency model ${ }^{6}$ with the standard model of $\mathrm{C}_{3}$ photosynthesis ${ }^{1}$, and successfully predicts gross primary production as measured at flux sites. This achievement is notable because of the equation's simplicity (with just two parameters, both independently estimated) and applicability across biomes and plant functional types. Thereby it provides a theoretical underpinning, grounded in eco-evolutionary principles, for large-scale analysis of the $\mathrm{CO}_{2}$ and water exchanges between atmosphere and land.

\section{Main}

Current Earth System Models (ESMs) disagree even on the most basic processes in the global carbon cycle, including terrestrial $\mathrm{CO}_{2}$ uptake ${ }^{2,3}$ - suggesting a need to revisit foundational questions in ecosystem science ${ }^{7,8}$. Depending on their history and purpose, ESMs represent plant $\mathrm{CO}_{2}$ uptake either with the standard model of Farquhar et al. ${ }^{1}$, which accurately describes the instantaneous environmental and physiological controls of photosynthesis, or with the empirical light use efficiency (LUE) model, which can predict primary production over weeks to months ${ }^{6,9}$. These approaches have served for the past three decades as parallel frameworks for relating primary production to environmental drivers, but the connection between them remains tenuous ${ }^{9}$. Moreover, large-scale implementations of both require independent information to be provided, such as photosynthetic capacities $\left(V_{c \max }\right.$ and $\left.J_{\max }\right)$ and the ratio of leaf-internal $\left(c_{i}\right)$ to ambient $\left(c_{a}\right) \mathrm{CO}_{2}$ concentrations (here termed $\chi$ ) in the Farquhar model, and response functions for various environmental factors in the LUE model. There is no accepted general way to do this ${ }^{10,11}$, and as a result, different implementations of apparently the same model can give very different answers in different ESMs.

The biochemical reactions of photosynthesis are critically dependent on the value of $\chi^{12} \cdot \mathrm{CO}_{2}$ diffuses into leaves through the stomata (microscopic pores in the leaf surface) towards the chloroplasts, where reducing power derived from solar energy is used to assimilate $\mathrm{CO}_{2}$ into organic forms through the Calvin cycle. $\chi$ is tightly regulated by the responses of stomatal aperture to environment. $\chi$ determines the availability of $\mathrm{CO}_{2}$ for assimilation, and thus constrains both the carboxylation- and electron transport-limited photosynthetic rates. However, current models that explicitly predict $\chi$ represent only its response to moisture, and even this is represented by several approximate and non-equivalent formulations (for more information on the theoretical background see Supplementary Methods S1) ${ }^{13}$. A firm basis for the prediction of $\chi$ is thus an essential step towards a first-principles representation of terrestrial plant carbon uptake. Here we derive a theory for the 
dependencies of $\chi$ on growing-season air temperature $\left(T_{g}\right)$, vapour pressure deficit VPD $\left(D_{g}\right)$, and elevation $(z)$ based on the least-cost hypothesis ${ }^{4,5}$, which states that plants minimize the combined costs of maintaining the capacities for carboxylation (maintaining the activity of Rubisco, the primary carboxylating enzyme, and other photosynthetic proteins) and transpiration (maintaining living tissues to support water transport) required to achieve a given assimilation rate. The theory is tested against effective growing-season values of $\chi$ derived from a global compilation of stable carbon isotope $\left(\delta^{13} \mathrm{C}\right)$ measurements on leaves of $\mathrm{C}_{3}$ plants (Fig. S1). The additional hypothesis of co-limitation between carboxylation- and electron transport-limited photosynthetic rates is then used to provide a universal model of gross primary production (GPP), which unifies the Farquhar and LUE models.

Logit transformation of the predicted optimal value of $\chi$ (termed $\chi_{o}$ ) yields remarkably simple theoretical partial relationships with each of the three environmental predictor variables (Supplementary Methods S2). The predicted effects of each variable are shown to be quantitatively consistent with those inferred from the data, within their uncertainties (Fig. 1, Table 1). Theory and data agree that logit $(\chi)$ rises by $\sim 0.0545$ per degree due to both increased assimilation costs (the affinity of Rubisco for $\mathrm{CO}_{2}$ versus $\mathrm{O}_{2}$ declines at higher temperatures) and reduced water transport costs (the viscosity of water also declines); falls by 0.5 per unit increase of $\ln D_{g}$ due to the increase in transpiration costs imposed by increasing $D$; and falls by $\sim 0.0815$ per km elevation due to reduced $\mathrm{O}_{2}$ pressure (increasing the affinity of Rubisco for $\mathrm{CO}_{2}$ ) and increased transpiration costs (because the saturated vapour pressure of water remains constant while the actual vapour pressure, ceteris paribus, declines). Thus, $\chi$ increases with temperature by $\sim 0.01 \mathrm{~K}^{-1}$, decreases with VPD by $\sim 0.1 \mathrm{kPa}^{-1}$, and decreases with elevation by $\sim 0.01 \mathrm{~km}^{-1}$. By imposing the theoretical values for the three environmental effects on $\chi$, we estimate an intercept of 1.189 , close to the fitted value of 1.168 . The fully linearized theoretical model is then:

$\operatorname{logit}\left(\chi_{\mathrm{o}}\right)=0.0545\left(T_{g}-25\right)-0.5 \ln D_{g}-0.0815 z+1.189$

which is statistically indistinguishable from the fitted model for $\chi$ (Table 1).

Equation (1) yields $\chi_{\mathrm{o}}=0.77$ under standard conditions $\left(T_{g}=25^{\circ} \mathrm{C}, D_{g}=1 \mathrm{kPa}, z=0 \mathrm{~km}\right)$. The predicted elevation effect increases with relative humidity $(\mathrm{RH})$, becoming arbitrarily large as $\mathrm{RH}$ approaches 100\% (Supplementary Methods S2). As predicted, the fitted (negative) slope of logit $(\chi)$ with elevation becomes larger with RH, most steeply at high RH (Fig. 1). Using an independent dataset of instantaneous $\mathrm{CO}_{2}$ and water exchange measurements ${ }^{14}$, we also show - consistent with equation (1) - that the single parameter determining the sensitivity of $\chi_{\mathrm{o}}$ to VPD is influenced by temperature, but not by VPD (Table S1).

$\chi_{\mathrm{o}}$ values from equation (1) are consistent with observed $\chi$ across biomes $(\mathrm{r}=0.51)$ (Fig. 2). Highest values are in hot, wet, low-elevation sites (tropical forests), lowest in cold and/or dry and/or high-elevation sites (deserts, polar and alpine vegetation). $\chi_{o}$ ranges globally from 0.4 to almost 1.0 (Fig. S2). The reduction from the equator towards mid-latitudes is due to aridity while that in high latitudes is due to declining temperatures (Fig. S3). The elevation effect on $\chi$ is long-known, but has not been satisfactorily explained ${ }^{15,16}$. By predicting it in the same framework that accounts for climate 
100 effects, we have resolved a long-standing conundrum, showing that the unit cost of photosynthesis is

101 reduced while that of transpiration is increased with elevation, leading to reduced $\chi_{o}$.

Some published analyses focused on leaf $\delta^{13} \mathrm{C}$ as a palaeoclimate indicator ${ }^{15,17,18}$. Unlike the well-documented effect of aridity on $\delta^{13} \mathrm{C}$, these analyses detected no temperature effect, even through it is predicted both by the earlier Cowan-Farquhar criterion ${ }^{19}$ and by the least-cost hypothesis ${ }^{4}$ and has been shown both in short-term experiments ${ }^{14,20}$ and in field data ${ }^{4}$. Mean annual precipitation (MAP) has previously been used to represent plant water availability; the lack of an observed temperature effect might then be an artefact, because MAP tends to increase with temperature. We showed a significant (but much weakened) effect of temperature when MAP was substituted for VPD (Table S2) based on our much larger data set. However the controlling variable is VPD, not MAP.

No significant difference was found between woody and non-woody plants (Fig. S4). The most parsimonious interpretation for the statistical significance of plant functional type (PFT) differences in $\chi$ detected here and elsewhere is as an indirect effect caused by different PFTs' climatic

113 preferences ${ }^{14}$. This interpretation is strongly supported by Fig. S4, which shows that differences in ${ }^{13} \mathrm{C}$ 114 discrimination among PFTs are predicted correctly by the universal model. We did however show a 115 slightly lower $\chi$ for evergreen needleleaf trees than the other PFTs (Fig. S4). This is consistent with 116 higher intrinsic water use efficiency in conifer forests than broadleaf forests, and could be attributed to 117 the lower permeability of gymnosperm wood (the consequence of narrower conducting elements) ${ }^{21}$. 118 According to our analysis, the estimated water cost is $20 \%$ higher in gymnosperms, even though the 119 resulting difference in $\chi$ from this component is slight (3\%: Supplementary Methods S2). The slightly 120 overestimated $\chi$ for evergreen needleleaf trees by the universal model, and the spread of observed $\chi$ 121 values around the central tendency, suggest that distinguishing hydraulic influences on the controls of unit transpiration costs, in particular, might further improve predictability.

We detected a significant negative response of $\chi$ to soil $\mathrm{pH}$, explaining an additional $5 \%$ of variance. This finding is consistent with a soil-calcium restoration experiment that enhanced annual evapotranspiration by $20 \%{ }^{22}$, and other findings of high $\chi$ on acid substrates ${ }^{23}$. The framework could be extended to consider $\mathrm{N}$ uptake costs, which may be higher (favouring investment in water transport) on less fertile soils.

The co-limitation hypothesis, stating that the two photosynthetic processes of carboxylation and transport are coupled such that photosynthetic rates limited by those two processes are equal under typical daytime conditions, provides the necessary next step towards a universal model of GPP ${ }^{24,25}$. The

131 hypothesis implies adjustment of $V_{c m a x}$ in time and space to match environmental conditions ${ }^{25}$.

132 Extensive field measurements also point to an optimal maximum rate of electron transport, $J_{\max }$ that 133 maximizes the photosynthetic benefits minus the costs of maintaining the electron-transport chain ${ }^{26}$ 134 (Supplementary Methods S4). We can thereby eliminate both $V_{c \max }$ and $J_{\max }$ as independent predictors, 135 to derive a first-principles model:

$136 \mathrm{GPP}=\varphi_{0} I_{a b s} m \sqrt{ }\left[1-\left(c^{*} / m\right)^{2 / 3}\right]$ 
Here $\varphi_{0}$ is the intrinsic quantum yield of photosynthesis $\left(1.02 \mathrm{~g} \mathrm{C} \mathrm{mol}^{-1}\right)^{27}, I_{a b s}$ is the absorbed photosynthetic photon flux density (PPFD, $\mathrm{mol} \mathrm{m}^{-2} \mathrm{~s}^{-1}$ ), $\Gamma^{*}$ is the photorespiratory compensation point (Pa), $\eta^{*}$ is the viscosity of water relative to its value at $25^{\circ} \mathrm{C}, \beta$ represents the ratio of carboxylation and transpiration costs at $25^{\circ} \mathrm{C}(\beta \approx 240$, estimated from the constant in equation 1$)$, and $c^{*}$ is the unit carbon cost for the maintenance of electron transport capacity, $\approx 0.41$ (estimated from observed $J_{\max }: V_{c \max }$ ratios) (Fig. S5). LUE is the product of $\varphi_{0}, m$ and the square-root term in equation (2); thus, GPP is proportional to $I_{a b s}$, which can be calculated from incident PPFD and remotely sensed green vegetation cover. Predicted monthly GPP compared well with monthly GPP derived from $\mathrm{CO}_{2}$ flux measurements (Fig. 3). Predicted global total annual GPP is $120 \mathrm{Pg} \mathrm{C}$, within the accepted range ${ }^{28}$.

Additional testable predictions arise, for example on the controls of net primary production (NPP). Our results intriguingly parallel findings from metabolic scaling theory, whereby monthly NPP was predicted and found to be proportional to growing-season length and biomass but to show a weakly negative response to temperature ${ }^{29}$. Many potential complications, such as the environmental dependencies of mesophyll conductance ${ }^{20}$, the influence of soil fertility factors on nutrient acquisition costs, and the differences among photosynthetic pathways, have been neglected so far; yet this simplistic model's predictive skill suggests a promising route to an improved predictive understanding of terrestrial carbon and water cycling.

\section{References}

1571 Farquhar, G. D., von Caemmerer, S. \& Berry, J. A. A biochemical model of photosynthetic $\mathrm{CO}_{2}$ assimilation in leaves of $\mathrm{C}_{3}$ species. Planta 149, 78-90 (1980).

1592 Ciais, P. et al. Carbon and other biogeochemical cycles. In: Climate Change 2013: the Physical Science Basis. Contribution of Working Group I to the Fifth Assessment Report of the Intergovernmental Panel on Climate Change. 465-570 (Cambridge University Press,

1633 Friedlingstein, P. et al. Uncertainties in CMIP5 climate projections due to carbon cycle feedbacks. Journal of Climate 27, 511-526 (2014). carbon gain and water transport: testing a new theoretical framework for plant functional ecology. Ecology letters 17, 82-91 (2014).

1685 Wright, I. J., Reich, P. B. \& Westoby, M. Least-cost input mixtures of water and nitrogen for photosynthesis. The American Naturalist 161, 98-111 (2003).

1706 Monteith, J. L. Solar radiation and productivity in tropical ecosystems. Journal of Applied Ecology 9, 747-766 (1972).

1727 Prentice, I. C., Liang, X., Medlyn, B. E. \& Wang, Y. P. Reliable, robust and realistic: the three R's of next-generation land-surface modelling. Atmospheric Chemistry and Physics 15, 59876005 (2015). 

176 (1998). Model Development Discussions 8, 6217-6266 (2015).

Cai, W. et al. Large differences in terrestrial vegetation production derived from satellitebased light use efficiency models. Remote Sensing 6, 8945-8965 (2014).

De Kauwe, M. G. et al. Forest water use and water use efficiency at elevated $\mathrm{CO}_{2}$ : a modeldata intercomparison at two contrasting temperate forest FACE sites. Global Change Biology 19, 1759-1779 (2013).

Medlyn, B. E. et al. Reconciling the optimal and empirical approaches to modelling stomatal conductance. Global Change Biology 17, 2134-2144 (2011).

Lin, Y.-S. et al. Optimal stomatal behaviour around the world. Nature Climate Change 5, 459-464 (2015).

Körner, C., Farquhar, G. D. \& Roksandic, Z. A global survey of carbon isotope discrimination in plants from high altitude. Oecologia 74, 623-632 (1988).

Friend, A., Woodward, F. \& Switsur, V. Field measurements of photosynthesis, stomatal conductance, leaf nitrogen and $\delta^{13} \mathrm{C}$ along altitudinal gradients in Scotland. Functional Ecology 3, 117-122 (1989).

Diefendorf, A. F., Mueller, K. E., Wing, S. L., Koch, P. L. \& Freeman, K. H. Global patterns in leaf ${ }^{13} \mathrm{C}$ discrimination and implications for studies of past and future climate. Proceedings of the National Academy of Sciences 107, 5738-5743 (2010).

Kohn, M. J. Carbon isotope compositions of terrestrial $\mathrm{C}_{3}$ plants as indicators of (paleo) ecology and (paleo) climate. Proceedings of the National Academy of Sciences 107, 1969119695 (2010). environment. Symposia of the Society for Experimental Biology 31, 471-505 (1977). Caemmerer, S. \& Evans, J. R. Temperature responses of mesophyll conductance differ greatly between species. Plant, Cell \& Environment 38, 629-637 (2015). Frank, D. C. et al. Water-use efficiency and transpiration across European forests during the Anthropocene. Nature Climate Change 5, 579-583 (2015). Green, M. B. et al. Decreased water flowing from a forest amended with calcium silicate. Proceedings of the National Academy of Sciences 110, 5999-6003 (2013). Global Ecology and Biogeography 24, 706-717 (2015).

24 Maire, V. et al. The coordination of leaf photosynthesis links $\mathrm{C}$ and $\mathrm{N}$ fluxes in $\mathrm{C}_{3}$ plant species. PloS One 7, e38345 (2012).

Haxeltine, A. \& Prentice, I. C. A general model for the light-use efficiency of primary production. Functional Ecology 10, 551-561 (1996). reanalysis of data from 36 species. Plant, Cell \& Environment 30, 1176-1190 (2007). 
21727 Long, S. P., Postl, W. F. \& Bolhar-Nordenkampf, H. R. Quantum yields for uptake of carbon

218 dioxide in $\mathrm{C}_{3}$ vascular plants of contrasting habitats and taxonomic groupings. Planta 189, 219 226-234 (1993).

22028 Beer, C. et al. Terrestrial gross carbon dioxide uptake: global distribution and covariation with $221 \quad$ climate. Science 329, 834-838 (2010).

22229 Michaletz, S. T., Cheng, D., Kerkhoff, A. J. \& Enquist, B. J. Convergence of terrestrial plant production across global climate gradients. Nature 512, 39-43 (2014).

Kaplan, J. O. Geophysical applications of vegetation modeling. (Doctoral Thesis, Lund University, 2001).

Acknowledgements

227 Research supported by an Australian Research Council Discovery grant ('Next-generation vegetation 228 model based on functional traits') to ICP and IJW, a National Basic Research Programme of China 229 (2013CB956602) grant to HW and CP, an Australian National Data Service grant ('Ecosystem 230 production in space and time') to ICP, and Terrestrial Ecosystem Research Council (TERN) grants 231 ('Ecosystem Modelling and Scaling Infrastructure') to ICP and BJE. TERN and ANDS are supported 232 by the Australian Government National Collaborative Infrastructure Strategy (NCRIS). TFK 233 acknowledges support from a Macquarie University Research Fellowship. We thank Yan-Shih Lin, 234 Vincent Maire, Belinda Medlyn and Beni Stocker for discussions. The paper is a contribution to the 235 AXA Chair Programme on Biosphere and Climate Impacts and Imperial College's initiative on Grand 236 Challenges in Ecosystems and the Environment. In addition to authors of this paper, data were 237 provided by Margaret Barbour, Lucas Cernusak, Todd Dawson, David Ellsworth, Graham Farquhar, 238 Howard Griffiths, Claudia Keitel, Alexander Knohl, Peter Reich, Dave Williams, Radika Bhaskar, 239 Hans Cornelissen, Anna Richards, Susanne Schmidt, Fernando Valladares, Christian Körner, Ernst240 Detlef Schulze, Nina Buchmann and Lou Santiago. We used 'free and fair use' eddy-covariance data 241 acquired by the FLUXNET community and, in particular, by the following networks: AmeriFlux (US 242 Department of Energy, Biological and Environmental Research, Terrestrial Carbon Program (DE243 FG02-04ER63917 and DE-FG02-04ER63911)), AsiaFlux, CarboEuropeIP, Fluxnet-Canada (supported 244 by CFCAS, NSERC, BIOCAP, Environment Canada, and NRCan), OzFlux and TCOS-Siberia. We 245 acknowledge the financial support to the eddy-covariance data harmonization provided by 246 CarboEuropeIP, FAO- GTOS-TCO, iLEAPS, Max Planck Institute for Biogeochemistry, National

247 Science Foundation, University of Tuscia, Université Laval and Environment Canada and US 248 Department of Energy and the database development and technical support from Berkeley Water 249 Center, Lawrence Berkeley National Laboratory, Microsoft Research eScience, Oak Ridge National 250 Laboratory, University of California-Berkeley, University of Virginia. 
bioRxiv preprint doi: https://doi.org/10.1101/040246; this version posted February 19, 2016. The copyright holder for this preprint (which

was not certified by peer review) is the author/funder. All rights reserved. No reuse allowed without permission.

252 Table 1 | Regression summaries. Logit-transformed values of the ratio of leaf-internal to ambient $\mathrm{CO}_{2}$

253 partial pressure $(\chi)$, derived from $\delta^{13} \mathrm{C}$ measurements, were regressed against the difference between

254 growing-season mean temperature $T_{g}$ and $25^{\circ} \mathrm{C}\left(\Delta T_{g},{ }^{\circ} \mathrm{C}\right)$, the natural logarithm of growing-season

255 mean VPD $\left(\ln D_{g}, \mathrm{kPa}\right)$, and elevation $(z, \mathrm{~km})$. Theoretical values are partial derivatives with respect to

256 each predictor, evaluated for standard conditions $\left(T_{g}=25^{\circ} \mathrm{C}, D_{g}=1 \mathrm{kPa}, z=0 \mathrm{~km}\right)$.

\begin{tabular}{rrrrrr}
\hline \multirow{2}{*}{ Predictor } & Fitted coefficient & \multicolumn{2}{c}{ Confidence intervals } & Theoretical & Model \\
& & $2.5 \%$ & $97.5 \%$ & value & $\mathrm{R}^{2}$ \\
\hline$\Delta T_{g}$ & 0.0515 & 0.0456 & 0.0575 & $\mathbf{0 . 0 5 4 5}$ & 0.391 \\
$\ln D_{g}$ & -0.5478 & -0.6111 & -0.4846 & $\mathbf{- 0 . 5}$ & \\
$z$ & -0.1065 & -0.1315 & -0.0815 & $\mathbf{- 0 . 0 8 1 5}$ & \\
intercept & 1.1680 & 1.0464 & 1.2896 & $\mathbf{1 . 1 8 9}$ \\
\hline
\end{tabular}


bioRxiv preprint doi: https://doi.org/10.1101/040246; this version posted February 19, 2016. The copyright holder for this preprint (which

was not certified by peer review) is the author/funder. All rights reserved. No reuse allowed without permission.

259 Figure 1 | Partial residual plots from the regression of logit-transformed $\chi$ against environmental

260 predictors. $\chi$, the ratio of leaf-internal to ambient $\mathrm{CO}_{2}$ partial pressures. $\Delta T_{g}$, = growing-season mean

261 temperature $T_{g}-25^{\circ} \mathrm{C} . \ln D_{g}$, natural logarithm of growing-season mean vapour pressure deficit. Inset

262 shows elevation responses for relative humidity (RH, \%) classes, compared to predicted responses

263 (black dots) evaluated at the centre of each class.

264

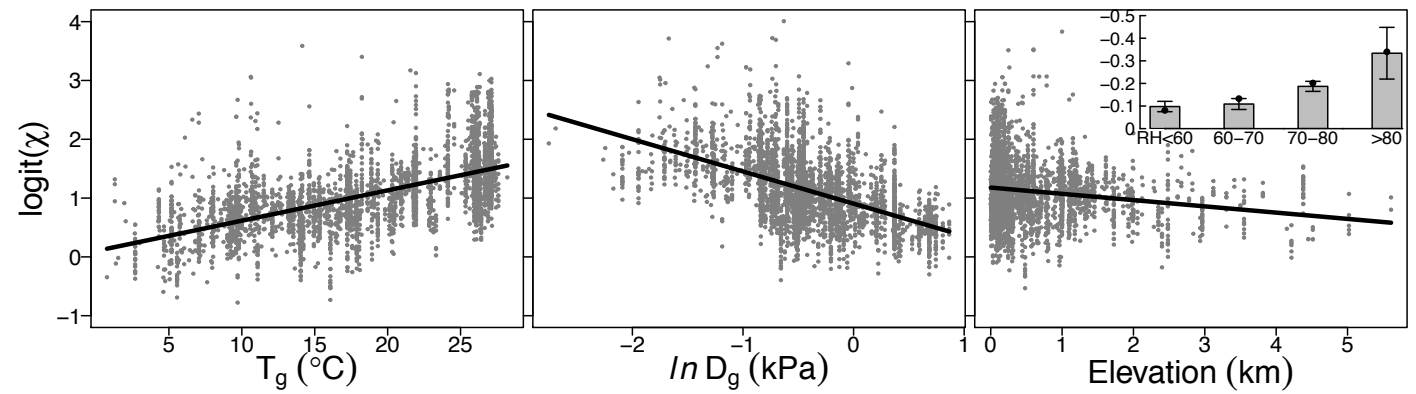


267 Figure 2 Site-mean leaf-internal to ambient $\mathbf{C O}_{2}$ partial pressures $(\chi)$. Predictions from the 268 theoretical model driven by three environmental variables (Table 1); observations from the global $\delta^{13} \mathrm{C}$ 269 dataset. Mean and standard deviation are shown for each biome. Biome type for each site were 270 assigned based on mega-biome classification from BIOME4 ${ }^{30}$ for consistency of definitions and 271 wetland and alpine types from literatures records. The regression line through the origin is imposed as 272 the black solid line; the dashed line is the $1: 1$ line.

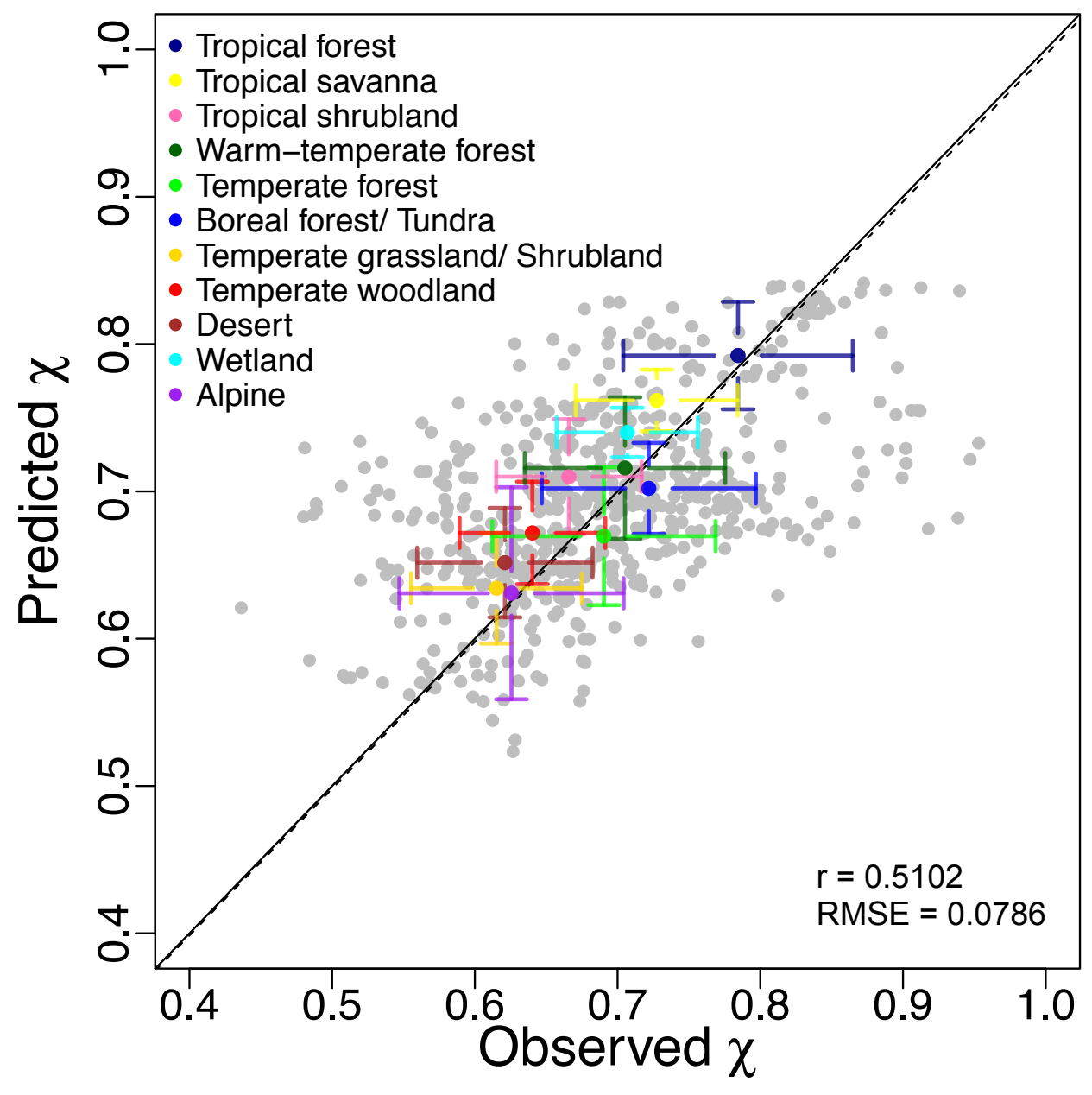


274 Figure 3 | Monthly gross primary production (GPP). Predictions from equations (2) and (3); 275 observations based on $\mathrm{CO}_{2}$ flux data in the FLUXNET archive. The regression line through the origin 276 is imposed as the black solid line; the dashed line is the $1: 1$ line.

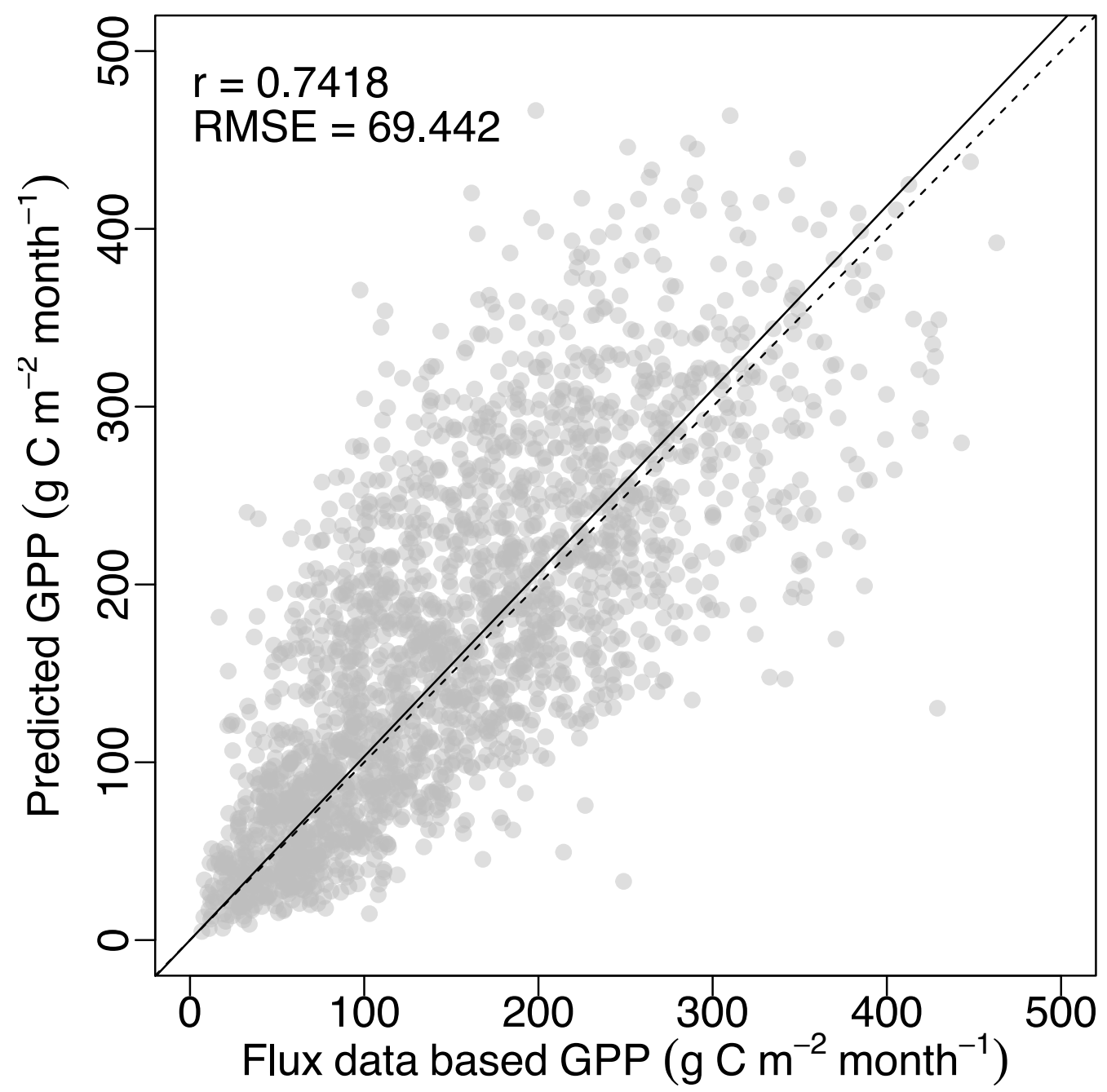




\section{Methods}

\section{Theory for the environmental controls on $\chi$}

281 According to the least-cost hypothesis ${ }^{4}$, optimal $\chi$ minimizes the combined costs of maintaining the capacities for carboxylation and transpiration:

$\chi=\xi /(\xi+\sqrt{ } D)$, where $\xi=\sqrt{ }(b K / 1.6 a)$.

284 The ratio of xylem repiration to transpiration capacity (a) depends inter alia on the viscosity of water; 285 the ratio of mitochondrial respiration to carboxylation capacity $(b)$ is generally taken as constant ${ }^{1} . D$ is 286 the vapour pressure deficit (VPD); $K$ is the effective Michaelis-Menten coefficient of Rubisco.

287 Logit transformation of (4) yields:

$\operatorname{logit}(\chi)=\ln [\chi /(1-\chi)]=1 / 2 \ln b-1 / 2 \ln a+1 / 2 \ln K-1 / 2 \ln D-1 / 2 \ln 1.6$

289 Temperature affects $\chi$ through $a$ via viscosity, and $K$ via the Michaelis-Menten coefficients for 290 carboxylation and oxygenation. Elevation affects $\chi$ through $K$ and $D$ via the partial pressures of oxygen and water vapour respectively. Separating environmental effects from invariant quantities in (5) leads to the definition of a constant term:

$C=1 / 2\left(\ln \beta+K_{r e f}-\ln 1.6\right)$

294 where $K_{r e f}$ and $\beta$ are the values of $K$ and the ratio $b / a$, respectively, under standard conditions $(T=298$ $295 \mathrm{~K}, z=0)$.

296 Using the Vogel equation for viscosity ${ }^{31}$, the Arrhenius equation for biochemical rate parameters and 297 the barometric formula relating atmospheric pressure to elevation, we evaluated the partial derivatives of $\chi$ with respect to $T, D$ and $z$ at $T=298 \mathrm{~K}, z=0$ and $D=1 \mathrm{kPa}$. $C$ was estimated as the intercept in a

299 Generalized Linear Model (GLM) fitted to the data with imposed regression coefficients (the calculated 300 partial derivatives) for all three environmental effects (Supplementary Methods S2).

\section{Testing the theory with global $\delta^{13} \mathbf{C}$ data}

302 Vascular-plant leaf stable carbon isotope data were compiled from published and unpublished sources 303 by Cornwell et al. (submitted). The data can be downloaded from Dryad (Data link 304 http://datadryad.org/review?doi=doi:10.5061/dryad.3jh61). Inferred carbon isotope discrimination $(\Delta)$ 305 values for 3549 leaf samples of $\mathrm{C}_{3}$ plants $^{32}$ (Supplementary Methods S3) were converted to estimates 306 of $\chi$ by a standard method. The Climatic Research Unit CL2.0 10-minute gridded monthly 307 climatology ${ }^{33}$ of mean, maximum and minimum temperatures and relative humidity provided mean 308 temperature $\left(T_{g},{ }^{\circ} \mathrm{C}\right)$ and vapour pressure deficit $\left(D_{g}, \mathrm{kPa}\right)$ values for the period with daily mean 309 temperatures $>0{ }^{\circ} \mathrm{C}$. Logit $(\chi)$ values were entered in a GLM with $\Delta T_{g}=T_{g}-25^{\circ} \mathrm{C}, \ln D_{g}$, and site310 specific elevation $(z, \mathrm{~km})$ as predictors. Standard errors estimated by the GLM were combined 
311 quadratically with standard errors for the uncertainty of the Rubisco discrimination parameter $b$ ', the 312 latter obtained by generating $10^{4}$ normally distributed values of $b^{\prime}$ (mean $=27$, standard deviation $=$

3130.27 ) and repeating the estimation of $\chi$ and the GLM fitting $10^{4}$ times with different $b$ ' values.

\section{$314 \quad$ Light-use efficiency model}

315 The model proposed by Wang et al. ${ }^{8}$ assumed that the electron-transport and Rubisco-limited rates of 316 photosynthesis $\left(A_{J}, A_{c}\right)$ are co-limiting under typical daytime conditions ${ }^{24,25,34}$, allowing GPP to be 317 predicted from $A_{J}$. LUE is the product of $\varphi_{0}$ and the $\mathrm{CO}_{2}$ limitation term (denoted here by $m$ ) in the 318 model of ref. 8. Incorporating the exact equation for $\chi_{o}$ (equation 8 in ref. 4) yields:

$$
A_{J}=\varphi_{0} I_{a b s} m, m=\frac{c_{a}-\Gamma^{*}}{c_{a}+2 \Gamma^{*}+3 \Gamma^{*} \sqrt{\frac{1.6 D \eta^{*}}{\beta\left(K+\Gamma^{*}\right)}}}
$$

320 However, (7) implies that the light response of $A_{J}$ is linear up to the co-limitation point, i.e. the maximum electron-transport rate $\left(J_{\max }\right)$ is arbitrarily large. In reality $J_{\max }$ limitation can be be significant, especially at high temperatures. We therefore modify (7) to consider a non-rectangular

323 hyperbola relationship between $A_{J}$ and $I_{a b s}{ }^{35,36}$ :

$$
A_{J}=\varphi_{0} I_{a b s} m \frac{1}{\sqrt{1+\left(\frac{4 \varphi_{0} I_{a b s}}{J_{\max }}\right)^{2}}}
$$

325 We further assume that there is a cost associated with $J_{\max }$ equal to the product of $J_{\max }$ and a constant $\left(c^{*}\right)$, and that optimal $J_{\max }$ maximizes the benefit $\left(A_{J}\right)$ minus this cost. The optimal ratio $J_{\max } / V_{c \max }$ at the 327 growth temperature is then:

$$
\frac{J_{\max }}{V_{c \max }}=\frac{4}{\left(c_{i}+K\right)} \sqrt[3]{\frac{\left(c_{i}-\Gamma^{*}\right)\left(c_{i}+2 \Gamma^{*}\right)^{2}}{c^{*}}}
$$
consistent with observations $^{26}$. The LUE model is accordingly revised to (Supplementary Methods S4):

$$
A_{J}=\varphi_{0} I_{a b s} m \sqrt{1-\left(\frac{c^{*}}{m}\right)^{\frac{2}{3}}}, m=\frac{c_{a}-\Gamma^{*}}{c_{a}+2 \Gamma^{*}+3 \Gamma^{*} \sqrt{\frac{1.6 D \eta^{*}}{\beta\left(K+\Gamma^{*}\right)}}}
$$


335 Equations (2)-(3) yielded modelled site-specific monthly GPP values for comparison with values 336 independently derived from eddy-covariance measurements of $\mathrm{CO}_{2}$ exchange in the Free and Fair Use 337 subset of the FLUXNET archive, using a consistent gap-filling procedure (Supplementary Methods S5). For the modelled values, monthly LUE was estimated based on temperature and vapour pressure

339 extracted from CRU time-series (TS 3.22) data at $0.5^{\circ} \mathrm{C}$ resolution ${ }^{38}$ and site-observed $c_{a}$. Monthly

340 absorbed PPFD was estimated as the product of PPFD (0.45 times the WATCH incident surface

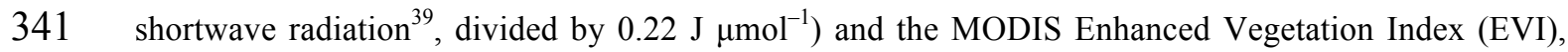

342 equated to the fraction of photosynthetically active radiation absorbed by foliage ${ }^{40}$. To match the

343 WATCH data resolution, EVI was upscaled to the $0.5^{\circ}$ grid cell in which each site was located.

\section{References}

34731 Vogel, H. Temperaturabhängigkeitsgesetz der Viskosität von Flüssigkeiten. Physik Z 22, 645$348 \quad 646(1921)$.

34932 Farquhar, G. D., Ehleringer, J. R. \& Hubick, K. T. Carbon isotope discrimination and $350 \quad$ photosynthesis. Annual Review of Plant Biology 40, 503-537 (1989).

35133 New, M., Lister, D., Hulme, M. \& Makin, I. A high-resolution data set of surface climate over 352 global land areas. Climate Research 21, 1-25 (2002).

35334 Chen, J.-L., Reynolds, J. F., Harley, P. C. \& Tenhunen, J. D. Coordination theory of leaf nitrogen distribution in a canopy. Oecologia 93, 63-69 (1993).

35535 Smith, E. L. The influence of light and carbon dioxide on photosynthesis. The Journal of general physiology 20, 807-830 (1937). cotton grown in elevated $\mathrm{CO}_{2}$. Plant, Cell \& Environment 15, 271-282 (1992). New, M., Hulme, M. \& Jones, P. Representing twentieth-century space-time climate variability. Part I: Development of a 1961-90 mean monthly terrestrial climatology. Journal of Climate 12, 829-856 (1999). Harris, I., Jones, P., Osborn, T. \& Lister, D. Updated high-resolution grids of monthly climatic

36840 Xiao, X., Zhang, Q., Hollinger, D., Aber, J. \& Moore, B. I. Modeling gross primary observations-the CRU TS3.10 Dataset. International Journal of Climatology 34, 623-642 (2014). Applications 15, 954-969 (2005). 
bioRxiv preprint doi: https://doi.org/10.1101/040246; this version posted February 19, 2016. The copyright holder for this preprint (which

was not certified by peer review) is the author/funder. All rights reserved. No reuse allowed without permission.

372 The least-cost theory was first proposed by I.J.W. and further developed by I.C.P. I.C.P. and H.W.

373 derived the predictions. H.W. carried out all the analyses and constructed the Figures and Tables.

374 W.K.C. originated and compiled the $\Delta^{13}$ C data set. B.J.E., T.W.D. and I.C.P. developed and tested the

375 flux partitioning method; T.W.D. developed the global flux database and all the GPP computations.

376 T.F.K contributed on quantifying the regression uncertainties. H.W. and I.C.P. wrote the first draft; all

377 authors contributed to the final draft.

378 